\title{
Deteksi Lembar Jawaban Komputer Menggunakan OMR (Optical Mark Recognition) Di MTS Nurul Iman
}

\author{
Moh. Novi Hermawan ${ }^{* 1}$, Maulidiansyah1 ${ }^{2}$, Sudriyanto ${ }^{3}$ \\ ${ }^{1,2,3}$ Prodi Informatika Fakultas Teknik Universitas Nurul Jadid \\ Karanganyar Paiton Probolinggo \\ e-mail: ${ }^{1 *}$ novi.prolink@gmail.com, ${ }^{2}$ maulid@unuja.ac.id, ${ }^{3}$ sudriyanto@unuja.ac.id
}

\begin{abstract}
Abstrak
Ujian konvensional atau ujian manual telah dilaksanakan beberapa dekade yang lalu dan masih digunakan sampai sekarang. Jenis tes ini menggunakan alat tulis sebagai media tes, seperti kertas, pensil, pena, dan jawaban tes ditulis tangan. Salah satu cara untuk menilai keberhasilan proses pengajaran di sekolah adalah dengan melaksanakan ujian. Dalam pelaksanaan ujian yang ada di MTS Nurul Iman menggunakan lembar jawaban komputer sebagai isiannya. Sedangkan sekolah wajib mempunyai alat scanner tertentu yang memiliki harga mahal untuk mengkoreksi lembar jawaban komputer. Alternatif lain yang bisa dilakukan sekolah adalah mengoreksi lembar jawaban komputer secara manual, akan tetapi hal tersebut membuat banyak waktu terbuang, serta bisa menyebabkan kesalahan dalam mengoreksi dan produkifitas kerja lambat. Dari permasalahan yang telah di uraikan, untuk mendeteksi lembar jawaban komputer tersebut dibutuhkan suatu metode. Melalui penelitian ini diharapkan dapat dikembangkan suatu metode yang secara otomatis mendeteksi pilihan jawaban pada lembar jawaban komputer, sehingga diperoleh hasil yang lebih akurat dan cepat. Berdasarkan permasalahan dari penelitian ini maka peneliti menggunakan metode OMR (Optical Mark Recognition) untuk mendeteksi lembar jawaban komputer secara otomatis dimana dalam tahapannya juga menggunakan metode canny, threshold, dan contour sorting. Dari hasil uji coba dapat disimpulkan bahwa tingkat akurasi deteksi lembar jawaban komputer dengan menggunakan OMR adalah $97 \%$.
\end{abstract}

Kata kunci: Ujian konvensional, Lembar Jawaban Komputer, Metode Canny, Threshold, OMR (Optical Mark Recognition, Countur Sorting.

\section{Abstract}

Conventional exams or manual exams were implemented decades ago and are still used today. This type of test uses writing instruments as test media, such as paper, pencil, pen, and handwritten test answers. One way to assess the success of the teaching process in schools is to carry out exams. In the implementation of the exam at MTS Nurul Iman, he used a computer answer sheet as an entry. Meanwhile, schools are required to have certain scanners that are expensive to correct computer answer sheets. Another alternative that can be done by schools is to manually correct computer answer sheets, but this makes a lot of time wasted, and can cause errors in correcting and slow work productivity. From the problems that have been described, to detect the computer answer sheet, a method is needed. Through this research, it is hoped that a method can be developed that automatically detects the answer choices on the computer answer sheet, so that more accurate and faster results are obtained. Based on the problems of this study, the researchers used the OMR (Optical Mark Recognition) method to detect computer answer sheets automatically which in stages also used the canny, threshold, and contour sorting methods. From the test results, it can be concluded that the accuracy of detection of computer answer sheets using OMR is $97 \%$. 
Keywords: Conventional exam, Computer Answer Sheet, Canny, Threshold, OMR (Optical Mark Recognition, Countur Sorting.

\section{PENDAHULUAN}

Pendidikan merupakan salah satu elemen dasar kehidupan manusia. Di Indonesia dapat dilakukan tiga pendekatan pendidikan yaitu in-formal, formal dan non-formal [1].Sistem pendidikan yang tercantum di dalam Undang-Undang Nomor 20 tahun 2003 yaitu "pendidikan nasional berfungsi mengembangkan dan membentuk watak serta peradaban bangsa yang bermartabat dalam rangka mencerdaskan kehidupan bangsa, bertujuan untuk berkembangnya potensi pesertadidik agar menjadi manusia yang beriman dan bertaqwa kepada Tuhan Yang Maha Esa, berahlak mulia, sehat, berilmu, cakap, kreatif, mandiri dan menjadi warga negara yang demokratis serta bertanggung jawab" [2].

MTS Nurul Iman adalah sekolah yang ada di desa Sindetlami Kecamatan Besuk, menurut bapak Ach. Susanto, S.Pd selaku kepala sekolah MTS Nurul Iman ada 13 mata pelajaran yang di ajarkan ke peserta didik dan prosedur pembelajaran dilakukan setiap harinya sesuai jadwal pelajaran yang telah ditentukan oleh kepala sekolah. Selain melakukan kegiatan belajar di MTS Nurul Iman, peserta didik juga akan beberapa kali melaksanakan ujian untuk melihat kemampuan dan pemahaman terhadap materi [3], diantaranya yaitu Ulangan, Ujian Tengah Semester (UTS) dan Ujian Akhir Semester (UAS).

Ujian sekolah merupakan salah satu cara untuk melihat hasil pendidikan yang diterima oleh pelajar dan sekolah merupakan salah satu cara untuk memberikan pendidikan [4]. Ujian konvensional atau ujian manual telah dilaksanakan beberapa dekade yang lalu dan masih digunakan sampai sekarang. Jenis tes ini menggunakan alat tulis sebagai media tes, yaitu tes dilakukan dalam bentuk alat tulis umum seperti kertas, pensil, dan pena. Ujian merupakan salah satu cara untuk menilai keberhasilan proses pengajaran di sekolah. Dalam bidang pendidikan, ujian dirancang untuk mengukur kinerja siswa, sehingga siswa dapat memahami tingkat pemahamannya terhadap bidang pelajaran yang ditempuh. Ujian juga digunakan untuk mengukur dan mengevaluasi penyampaian mata pelajaran yang diajarkan oleh guru kepada siswa [5].

Menurut Akbar, R.M mengatakan bahwa Inovasi untuk mempercepat dan mempermudah proses mengkoreksi hasil ujian dengan mesin pemindai OMR yaitu menggunakan Lembar Jawaban Komputer (LJK). Formulir pendataan dan pendaftaran, kuesioner, serta ujian pilihan ganda biasanya menggunakan lembar jawaban komputer. Dalam pengisian data manual dapat membuat pemrosesan data menjadi cepat dengan menggunakan lembar jawaban komputer sebagai pengganti [6]. Dalam pelaksanaan ujian yang ada di MTS Nurul Iman menggunakan lembar jawaban komputer sebagai isiannya. Sedangkan pihak sekolah perlu mempunyai alat tertentu seperti scanner yang harganya mahal untuk proses mendeteksi pilihan pada lembar jawaban komputer. Alternatif lain yang bisa dilakukan sekolah adalah mengoreksi lembar jawaban komputer secara manual, akan tetapi hal tersebut membuat banyak waktu terbuang, serta bisa menyebabkan kesalahan dalam mengoreksi dan produkifitas kerja lambat.

OMR (Optical Mark Recognition) sendiri merupakan singkatan dari optical mark recognition, disebut juga optical mark reading, yang artinya pengenalan atau pembacaan tanda optik. OMR(Optical Mark Recognition) adalah proses menangkap data dari formulir dokumen seperti kuesioner dan ujian yang ditandai oleh manusia. OMR (Optical Mark Recognition) biasa membaca kuesioner, kertas ujian pilihan ganda berupa arsiran [7]. 
Untuk medeteksi lembar jawaban komputer dilakukan dengan menggunakan OMR (Optical Mark Recognition) yang di implementasikan menggunakan bahasa pemrograman python, karena python memiliki sintaks yang jelas oleh karena itu python termasuk bahasa pemograman yang mudah dipelajari [8]. Dalam penelitian ini lebih ditekankan pada deteksi lembar jawaban komputer untuk menguji tingkat akurasi metode OMR (Optical Mark Recognition) pada lembar jawaban komputer tersebut menggunakan IDE pycharm dan library opencv yang sering digunakan pada pengolahan citra computer vision [9]. Salah satu Integrated Development Environment (IDE) yang berfokus pada Bahasa pemograman python adalah pycharm [10]. Berdasarkan permasalahan di atas, dapat diambil solusi bagaimana menciptakan dan mendeteksi lembar jawaban komputer mengunakan OMR (Optical Mark Recognition) di MTS Nurul Iman.

\section{METODE PENELITIAN}

Dalam penelitian ini metode yang digunakan adalah untuk menghasilkan detaksi lembar jawaban computer secara otomatis sesuai dengan langkah-langkahnya. Proses dari penelitian ini meliputi pengumpulan data LJK, pre-processing, penerapan metode OMR (Optical Mark Recognition), deteksi jawaban, pengujian, dan penarikan kesimpulan. Gambar 1 adalah gambaran kerangka penelitian.

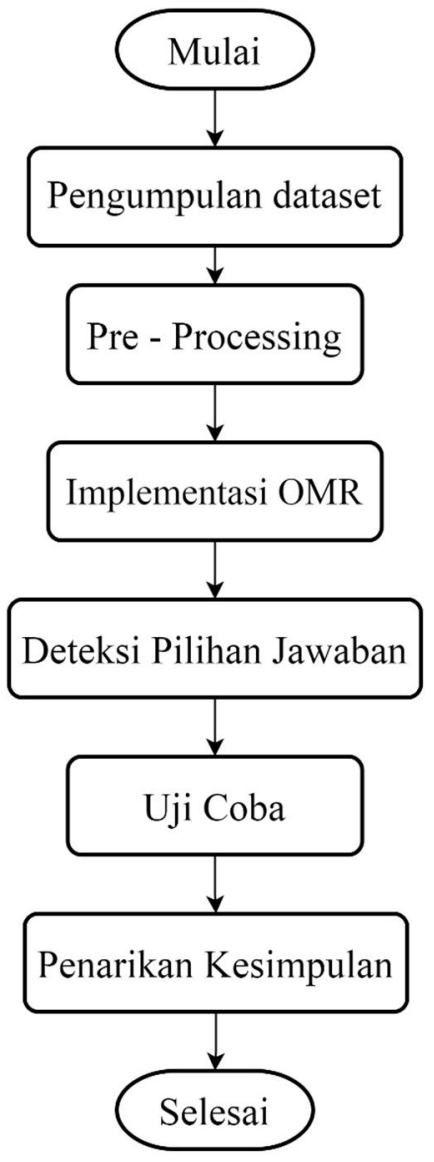

Gambar 1. Kerangka Peneitian 
Pada gambar 1 diatas dapat dijelaskan langkah yang dilakukan pada setiap tahapannya. Kerangka penelitian ini dapat dijabarkan sebagai berikut.

\subsection{Pengumpulan Dataset}

Dalam penelitian ini menggunakan 20 hasil scan lembar jawaban komputer di MTS Nurul Iman dimana 10 lembar jawaban komputer arsiran penuh, 4 hasil scan lembar jawaban komputer arsiran separuh, 5 hasil scan lembar jawaban komputer arsiran samar - samar dan 1 hasil scan lembar jawaban komputer arsiran yang salah.

\subsection{Pre-Processing}

Pada proses pre-processing, data yang telah dikumpulan dari tahapan sebelumnya, selanjutnya untuk mempermudah proses implementasi OMR terlebih dahulu akan diolah. Pada tahap pre-processing proses yang dilakukan adalah mendeteksi titik tepi obyek menggunakan metode canny. Sebelum dilakukan deteksi tepi canny terlebih dahulu dilakukan proses dengan mentransformasi citra asli menjadi citra greyscale dan selanjutnya adalah proses blur pada citra greyscale untuk menghilangkan noise pada citra lembar jawaban komputer.

\subsection{Implementasi OMR}

Setelah melakukan proses pre-processing dengan merubah citra asli menjadi citra abuabu dan deteksi tepi canny, proses selanjutnya adalah segmentasi dengan metode threshold. Untuk memisahkan objek dalam suatu citra dari background berdasarkan perbedaan kecerahannya menggunakan segmentasi. Jadi objek akan berwarna putih pada citra lembar jawaban komputer serta background akan berwarna hitam. Selanjutnya akan dilakukan deteksi tepi objek, hasil dari deteksi tepi objek adalah lingkaran yang sudah terdapat garis tepinya. Contour Sorting atau Pengurutan kontur lembar jawaban komputer dilakukan dari kiri ke arah kanan dengan mengurutkan bulatan yang terdapat pada lembar jawaban komputer.

\subsection{Deteksi Pilihan Jawaban}

Pada tahap ini proses yang dilakukan adalah mendeteksi jawaban yang dipilih atau diarsir. Selanjutnya dilakukan deteksi jawaban, cara yang dilakukan pada proses deteksi jawaban adalah mendeteksi bulatan lembar jawaban komputer yang telah diarsir. Jawaban yang terarsir akan dideteksi sebagai pilihan yang dipilih. Sebagai contoh jika pilihan B yang terarsir maka akan dideteksi jawaban tersebut sebagai indeks satu.

Hasil dari proses sebelumnya akan dicocokkan dengan file excel yang telah disimpan sebagai kunci jawaban. Hasil dari pemeriksaan lembar jawaban komputer selanjutnya dihitung jumlah jawaban yang benar. Dari proses pencocokan ini akan diketahui pilihan jawaban yang benar dan nilainya akan ditampilkan pada pojok kanan atas. Untuk mengetahui nilai dari jawaban yang benar menggunakan rumus sebagai berikut:

$$
\text { Nilai }=\left(\frac{\text { Jumlah Jawaban Benar }}{\text { Jumlah Soal }}\right) \times 100
$$

\subsection{Uji Coba}

Tahap uji coba akan membahas hasil deteksi yang telah dilakukan terhadap 21 gambar lembar jawaban komputer dimana 11 lembar jawaban komputer arsiran penuh, 4 lembar jawaban komputer arsiran separuh, 5 lembar jawaban komputer arsiran samar - samar dan 1 citra lembar jawaban komputer dengan arsiran yang salah, pada pengujian ini akan diperoleh tingkat presentase akurasi dari pendeteksian lembar jawaban komputer menggunakan rumus seperti dibawah ini :

Moh., et., al [Deteksi Lembar Jawaban Komputer Menggunakan OMR (Optical Mark Recognition) Di MTS Nurul Iman] 


$$
\text { presentase }=\left(\frac{\text { Jumlah Deteksi Benar }}{\text { Jumlah Total Soal }}\right) \times 100 \%
$$

Pengujian yang dilakukan berfokus pada metode OMR (Optical Mark Recognition) yang oleh peneliti diuji coba sendiri menggunakan python. Dari pengujian ini akan terlihat berhasil atau tidak dalam menggunakan metode OMR.

\subsection{Penarikan Kesimpulan}

Pada tahapan terakhir, kesimpulan dalam menggunakan metode OMR (Optical Mark Recognition) bisa di ambil dari tingkat akurasi deteksi lembar jawaban komputer yang di uji coba oleh sistem, serta penarikan kesimpulan bisa berguna bagi peneliti lain untuk mengembangkan penelitian tersebut dengan menggunakan metode lain agar lebih baik tingkat akurasinya.

\section{HASIL DAN PEMBAHASAN}

\subsection{Pengumpulan Dataset}

Dalam penelitian ini menggunakan 20 data hasil scan lembar jawaban komputer di MTS Nurul Iman dimana 10 lembar jawaban komputer arsiran penuh, 4 hasil scan lembar jawaban komputer arsiran separuh, 5 hasil scan lembar jawaban komputer arsiran samar - samar dan 1 hasil scan lembar jawaban komputer arsiran yang salah. Dibawah ini adalah contoh dataset yang digunakan.

a. Lembar Jawaban Komputer Arsiran penuh

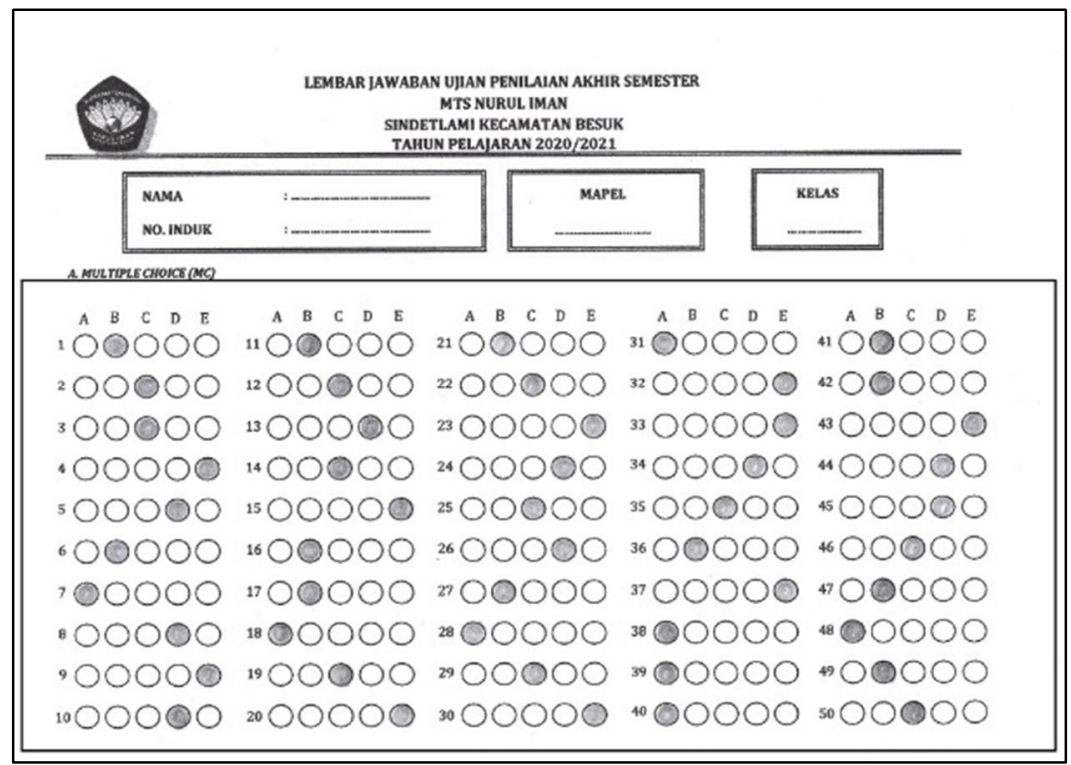

Gambar 2. Lembar Jawaban Komputer Arsiran Penuh 
b. Lembar Jawaban Komputer Arsiran Separuh

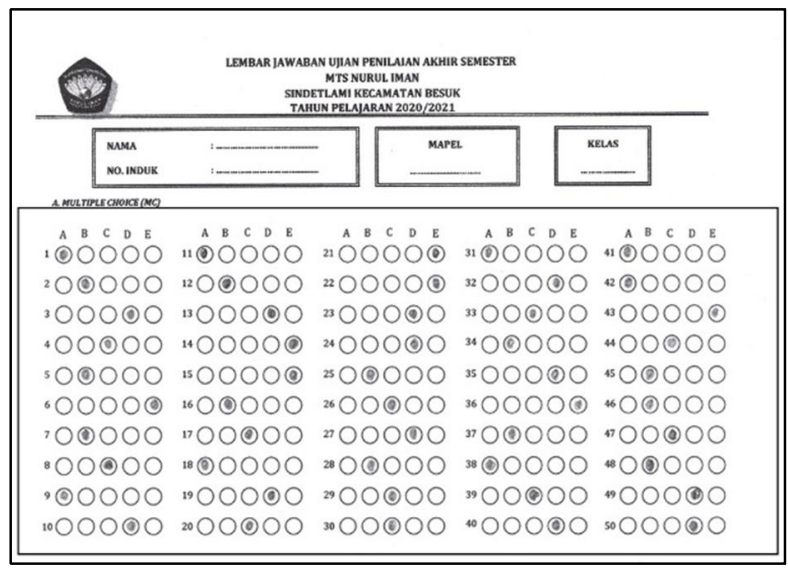

Gambar 3. Lembar Jawaban Komputer Arsiran Separuh

c. Lembar Jawaban Komputer Arsiran Samar - Samar

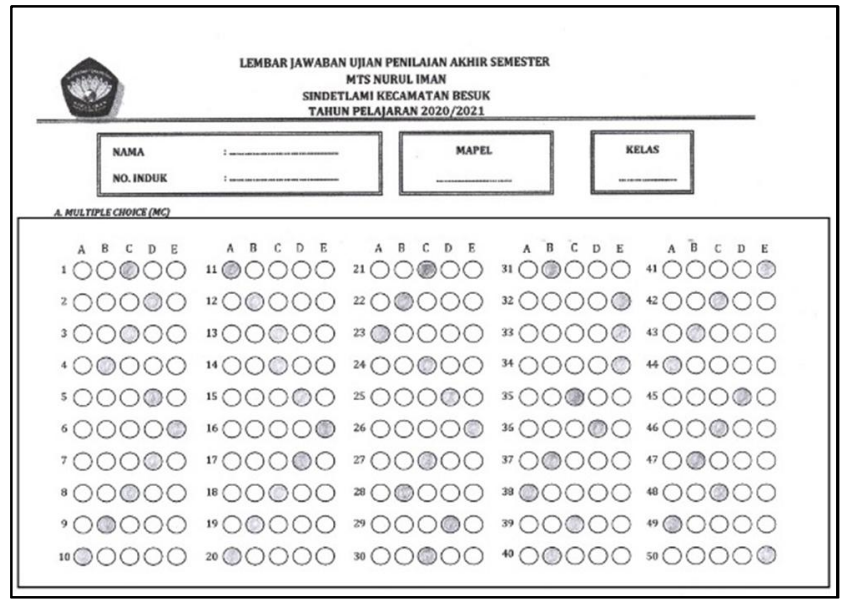

Gambar 4. Lembar Jawaban Komputer Arsiran Samar - samar

d. Lembar Jawaban Komputer Arsiran yang salah

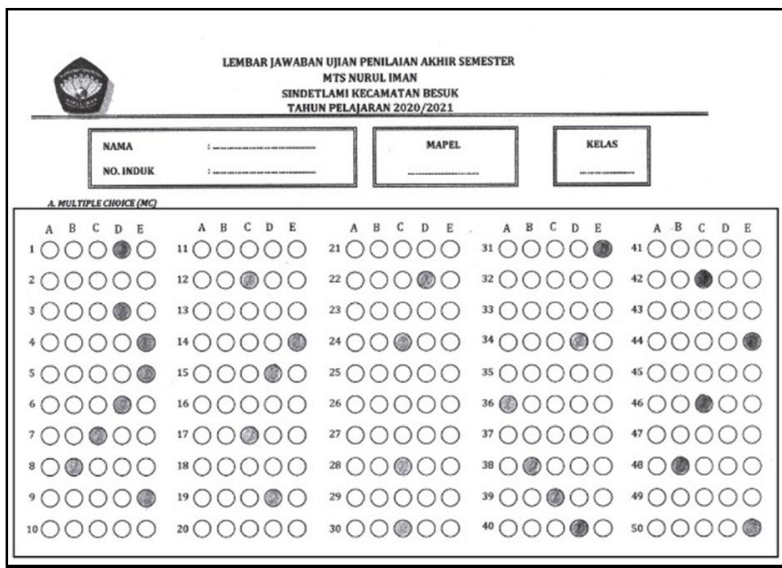

Gambar 5. Lembar Jawaban Komputer Arsiran yang Salah 


\subsection{Pre-Processing}

Dalam proses pre-processing, data yang telah dikumpulan dari tahapan sebelumnya, selanjutnya untuk mempermudah proses implementasi OMR terlebih dahulu akan diolah. Pada tahap pre-processing proses yang dilakukan adalah mendeteksi titik tepi obyek menggunakan metode canny. Sebelum dilakukan deteksi tepi canny terlebih dahulu dilakukan proses dengan mentransformasi citra asli menjadi citra greyscale dan selanjutnya dilakukan proses bluring pada citra grayscale untuk menghilangkan noise pada citra lembar jawaban komputer. Pemrosesan selanjutnya adalah proses deteksi tepi canny, kemudian dilakukan proses croping untuk mendapatkan citra dari isian bulatan lembar jawaban komputer.

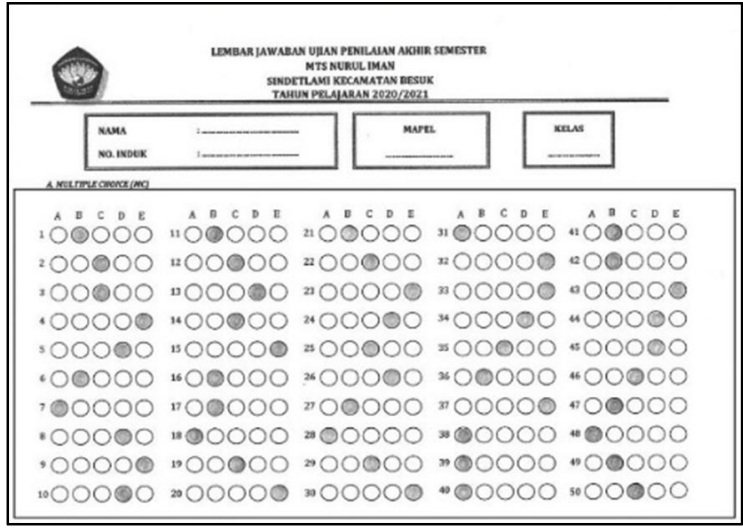

(a)

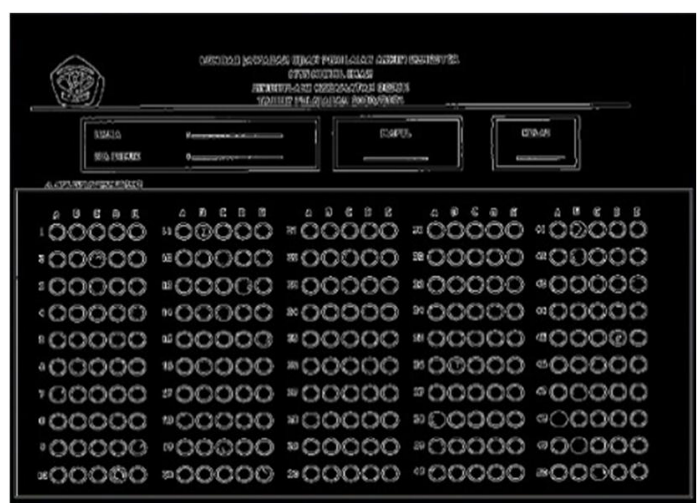

(c)

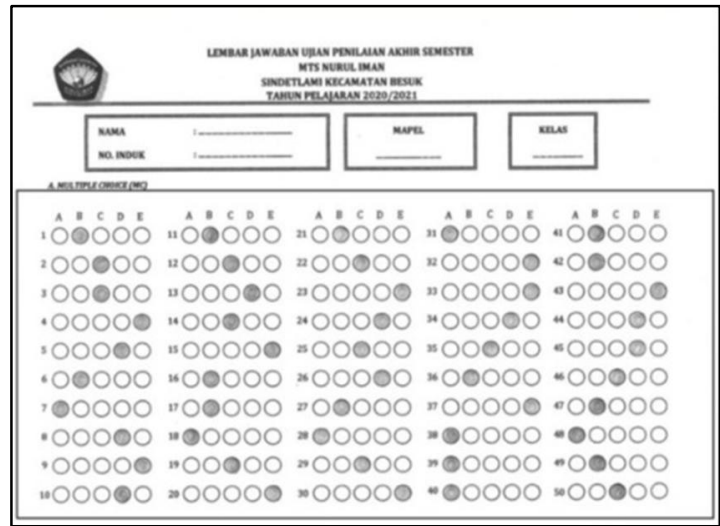

(b)

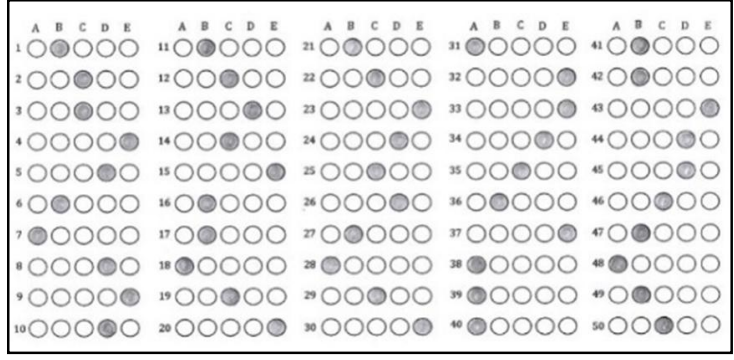

(d)

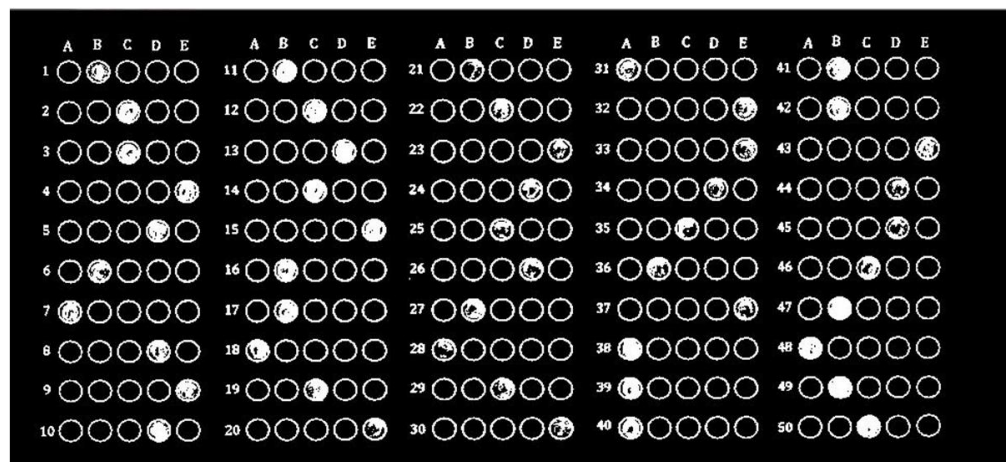

Gambar 6. Hasil Deteksi Tepi Canny

(a) Citra gray (b) Citra Blur (c) Canny (d) Hasil cropping 


\subsection{Implementasi OMR}

Setelah melakukan tahap sebelumnya dengan merubah citra asli menjadi citra abu-abu dan deteksi tepi canny, proses selanjutnya adalah segmentasi dengan metode threshold. Untuk memisahkan objek dalam suatu citra dari background berdasarkan perbedaan kecerahannya menggunakan segmentasi. Jadi objek berwarna putih pada citra lembar jawaban komputer serta background berwarna hitam.

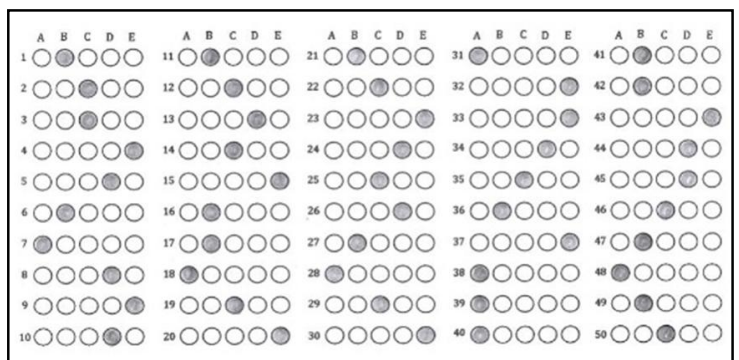

(a)

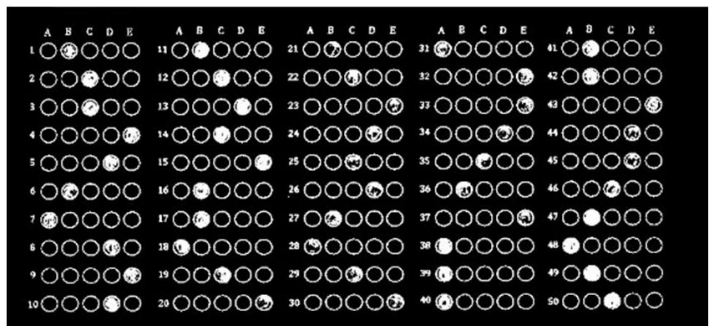

(b)

Gambar 7. Hasil Metode threshold

(a) Hasil cropping (b) Hasil threshold

Selanjutnya akan dilakukan deteksi tepi objek, hasil dari deteksi tepi objek adalah lingkaran yang sudah terdapat garis tepinya. Contour Sorting atau Pengurutan kontur lembar jawaban komputer dilakukan dari kiri ke arah kanan dengan mengurutkan bulatan yang terdapat pada lembar jawaban computer

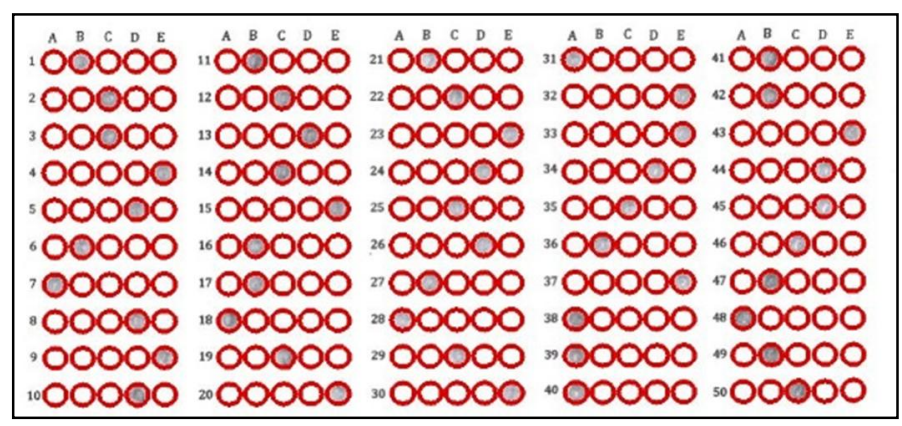

Gambar 8. Hasil Countur Sorting

\subsection{Deteksi Pilihan Jawaban}

Pada tahap ini proses yang dilakukan adalah mendeteksi jawaban yang dipilih atau diarsir. Selanjutnya dilakukan deteksi jawaban, cara untuk deteksi jawaban adalah mendeteksi bulatan lembar jawaban komputer yang telah diarsir. Jawaban yang terarsir akan dideteksi sebagai pilihan yang dipilih. Sebagai contoh jika pilihan B yang terarsir maka akan dideteksi jawaban tersebut sebagai indeks satu 


\begin{tabular}{|c|c|}
\hline B & C \\
\hline NO & KUNCI JAWABAN \\
\hline 1 & D \\
\hline 2 & B \\
\hline 3 & D \\
\hline 4 & C \\
\hline 5 & C \\
\hline 6 & E \\
\hline 7 & B \\
\hline 8 & C \\
\hline 9 & A \\
\hline 10 & E \\
\hline
\end{tabular}

(a)

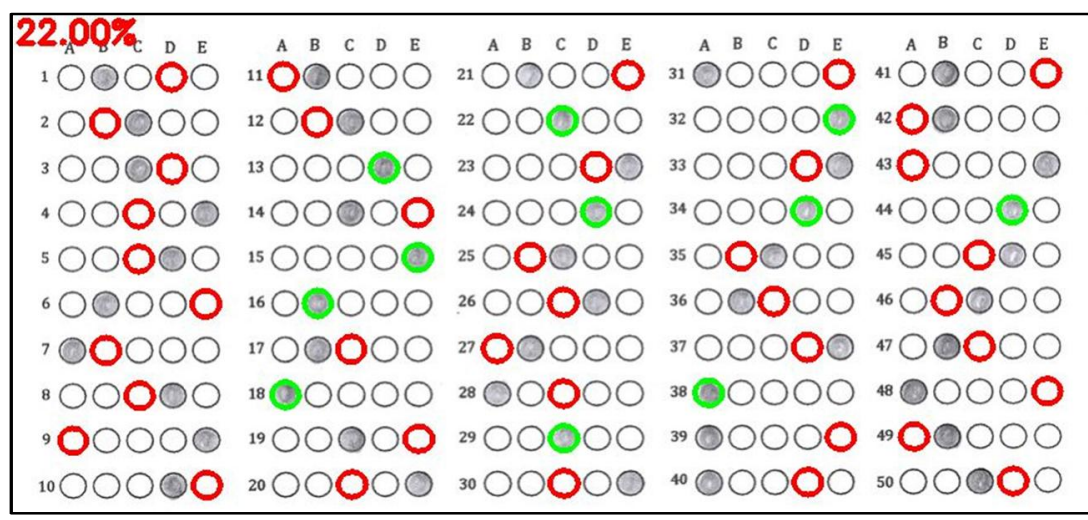

(b)

Gambar 9 Deteksi Pilihan Jawaban

(a) Kunci jawaban (b) Hasil deteksi pilihan jawaban

Hasil dari proses sebelumnya akan dicocokkan dengan file excel yang telah disimpan sebagai kunci jawaban. Hasil dari pemeriksaan lembar jawaban komputer selanjutnya dihitung jumlah jawaban yang benar. Dari proses pencocokan ini akan diketahui pilihan jawaban yang benar dan nilainya akan ditampilkan pada pojok kanan atas.

$$
\begin{aligned}
\text { Nilai } & =\left(\frac{\text { Jumlah Jawaban Benar }}{\text { Jumlah Soal }}\right) \times 100 \\
& =\left(\frac{11}{50}\right) \times 100=22
\end{aligned}
$$

\subsection{Uji Coba}

Tahap uji coba akan membahas hasil deteksi yang telah dilakukan terhadap 20 citra hasi scan lembar jawaban komputer dimana 10 lembar jawaban komputer arsiran penuh, 4 lembar jawaban komputer arsiran separuh, 5 lembar jawaban komputer arsiran samar - samar dan 1 citra lembar jawaban komputer dengan arsiran yang salah.

\begin{tabular}{|c|c|c|c|c|c|}
\hline No. & Data Citra & $\begin{array}{c}\text { Deteksi } \\
\text { Benar }\end{array}$ & $\begin{array}{c}\text { Deteksi } \\
\text { Salah }\end{array}$ & Total Soal & Akurasi \\
\hline 1 & Ljk_penuh_1.jpg & 50 & 0 & 50 & $100 \%$ \\
\hline 2 & Ljk_penuh_2.jpg & 50 & 0 & 50 & $100 \%$ \\
\hline 3 & Ljk_penuh_3.jpg & 50 & 0 & 50 & $100 \%$ \\
\hline 4 & Ljk_penuh_4.jpg & 50 & 0 & 50 & $100 \%$ \\
\hline 5 & Ljk_penuh_5.jpg & 48 & 2 & 50 & $96 \%$ \\
\hline 6 & Ljk_penuh_6.jpg & 48 & 2 & 50 & $96 \%$ \\
\hline 7 & Ljk_penuh_7.jpg & 48 & 2 & 50 & $96 \%$ \\
\hline 8 & Ljk_penuh_8.jpg & 49 & 1 & 50 & $98 \%$ \\
\hline 9 & Ljk_penuh_9.jpg & 49 & 1 & 50 & $98 \%$ \\
\hline 10 & Ljk_penuh_10.jpg & 50 & 0 & 50 & $100 \%$ \\
\hline 11 & Ljk_separuh_1.jpg & 48 & 2 & 50 & $96 \%$ \\
\hline 12 & Ljk_separuh_2.jpg & 45 & 5 & 50 & $90 \%$ \\
\hline
\end{tabular}

Moh., et., al [Deteksi Lembar Jawaban Komputer Menggunakan OMR (Optical Mark Recognition) Di MTS Nurul Iman] 


\begin{tabular}{|c|c|c|c|c|c|}
\hline 13 & Ljk_separuh_3.jpg & 49 & 1 & 50 & $98 \%$ \\
\hline 14 & Ljk_separuh_4.jpg & 49 & 1 & 50 & $98 \%$ \\
\hline 15 & Ljk_samar_1.jpg & 49 & 1 & 50 & $98 \%$ \\
\hline 16 & Ljk_samar_2.jpg & 47 & 3 & 50 & $94 \%$ \\
\hline 17 & Ljk_samar_3.jpg & 49 & 1 & 50 & $98 \%$ \\
\hline 18 & Ljk_samar_4.jpg & 50 & 0 & 50 & $100 \%$ \\
\hline 19 & Ljk_samar_5.jpg & 48 & 2 & 50 & $96 \%$ \\
\hline 20 & Ljk_salah.jpg & 44 & 6 & 50 & $88 \%$ \\
\hline \multicolumn{2}{|c|}{ Total } & 970 & 32 & 1000 & $97 \%$ \\
\hline
\end{tabular}

Pada tabel 4.2 untuk mendapatkan nilai akurasi deteksi Lembar Jawaban Komputer dilakukan menggunakan rumus sebagai berikut:

Sehingga didapat

$$
\text { Akurasi }=\left(\frac{\text { Jumlah Deteksi Benar }}{\text { Jumalah total soal }}\right) 100 \%
$$

$$
\text { Akurasi }=\left(\frac{970}{1000}\right) 100 \%=97 \%
$$

\subsection{Penarikan Kesimpulan}

Adapun hasil deteksi yang dilakukan dengan 20 data uji yaitu deteksi citra lembar jawaban komputer dengan arsiran penuh, uji coba citra lembar jawaban komputer dengan arsiran separuh, uji coba citra lembar jawaban komputer dengan arsiran samar - samar dan uji coba citra lembar jawaban komputer dengan arsiran yang salah.

Pada tahap uji coba 20 lembar jawaban komputer sebagai dataset yang dilakukan mendapatkan hasil dengan tingkat akurasi untuk data uji lembar jawaban komputer arsiran penuh, untuk data uji lembar jawaban komputer arsiran separuh, untuk data uji lembar jawaban komputer arsiran samar - samar dan untuk data uji lembar jawaban komputer arsiran yang salah total adalah $97 \%$.

\section{KESIMPULAN}

Berdasarkan permasalahan penelitian yang telah dilakukan dari percobaan dan dibahas secara detail dapat disimpulkan bahwa dari 20 dataset yang diuji coba menggunakan metode OMR (Optical Mark Recognition) dengan 10 data uji lembar jawaban komputer arsiran penuh, 4 data uji lembar jawaban komputer arsiran separuh, 5 data uji lembar jawaban komputer arsiran samar - samar dan 1 data uji lembar jawaban komputer dengan kesalahan arsiran. Mengunakan bebarapa tahapan serta menghasilkan nilai akurasi deteksi lembar jawaban komputer di MTS Nurul Iman dengan tingkat akurasi 97\%. Lembar jawaban komputer dengan pengisian arsiran yang melebihi bulatan serta hasil scan dengan kualitas buruk tidak berhasil dideteksi.

\section{SARAN}

Berdasarkan kesimpulan di atas, adapun saran untuk menyempurnakan penelitian dan aplikasi yang dibuat sebagai berikut:

1. Aplikasi deteksi lembar jawaban dapat di kembangkan dengan mengunakan metode lain. Agar memiliki akurasi yang lebih tinggi dan hasil deteksi yang bagus. 
2. Untuk meningkatkan akurasi proses deteksi lembar jawaban komputer perlu ditambahkan algoritma yang lebih kompleks sehingga dapat mendeteksi lembar jawaban komputer secara realtime menggunakan kamera.

3. Deteksi lembar jawaban komputer dapat dikembangkan dengan menggunakan android. Agar memudahkan dalam pengambilan gambar.

\section{UCAPAN TERIMA KASIH}

Penulis sampaikan terima kasih yang sebesar-besarnya kepada pihak MTS Nurul Iman yang telah memperkenankan daam melakukan penelitian dan semua pihak yang telah mendukung, sehingga penulis dapat menyelesaikan Deteksi Lembar Jawaban Komputer Menggunakan Omr (Optical Mark Recognition) Di Mts Nurul Iman.

\section{DAFTAR PUSTAKA}

[1] Wicaksono, A. G. 2018, Fenomena Full Day School Dalam Sistem Pendidikan Indonesia. Jurnal Komunikasi Pendidikan, 1(1), 10. https://doi.org/10.32585/jkp.v1i1.12

[2] Rosyad, A. M. 2019, Implementasi Pendidikan Karakter Melalui Kegiatan Pembelajaran di Lingkungan Sekolah. Tarbawi: Jurnal Keilmuan Manajemen Pendidikan, 5(02), 173190. https://doi.org/10.32678/tarbawi.v5i02.2074

[3] Nurhasanah. 2018, Pengembangan Tes Untuk Mengukur Kemampuan Penalaran Mahasiswa Mata Kuliah Geometri. Pepatudzu: Media Pendidikan dan Sosial Kemasyarakatan, 14(1), 62. https://doi.org/10.35329/fkip.v14i1.186

[4] Putra, R. R. C., \& Sugihartono, T. 2019, Penerapan Algoritma Fisher-Yates Shuffle pada Computer Based Test Ujian Sekolah di SMKN 1 Payung. MATRIK: Jurnal Manajemen, Teknik Informatika dan Rekayasa Komputer, 18(2), 276-283. https://doi.org/10.30812/matrik.v18i2.399

[5] Sampebua, M. R., \& Membala, S. B. 2018, Penerapan Aplikasi Ujian Berbasis Komputer Untuk Meningkatkan Kualitas Pendidikan pada Smp. Jurnal Pengabdian Рариа, 2(1), 24-31.

[6] Akbar, R., Silvana, M., \& Alizar, A. F. 2019, Perancangan Aplikasi Pembayaran Non Tunai Untuk Pengelolaan Bisnis Pencucian Mobil Dengan Memanfaatkan Teknologi QR Code (Studi Kasus: Oto Pro Car Wash \& Detailling Padang ). 3. jurnal.umj.ac.id/index.php/semnastek

[7] Idris, S. 2020, Diklat Optical Mark Recognition Evaluator Sebagai Media Peningkatan Efisiensi Guru Dalam Pemeriksaan dan Analisis Hasil Ulangan Siswa di Al-Fajar Academy Mataram Tahun 2020. 2, 76-79.

[8] Zulkhaidi, T. C. A.-S., Maria, E., \& Yulianto, Y. 2020, Pengenalan Pola Bentuk Wajah Dengan OpenCV. Jurnal Rekayasa Teknologi Informasi (JURTI), 3(2), 181. https://doi.org/10.30872/jurti.v3i2.4033 
[9] Tryatmojo, B., \& Maryati, R. I. S. 2019, Akurasi Sistem Face Recognition OpenCV Menggunakan Raspberry Pi Dengan Metode Haar Cascade. Jurnal Ilmiah Informatika (JIF), 7(2), 92-98.

[10] Thariq, A., \& Yusliana, R. 2021, Sistem Deteksi Masker Dengan Metode Haar Cascade pada Era New Normal COVID-19 Mask Detection System using Haar Cascade Method in New Normal Era of COVID-19. 9(2), 241-244. https://doi.org/10.26418/justin.v9i2.44309 